\title{
COVID-19 and the Opioid Epidemic: Two Public Health Emergencies That Intersect With Chronic Pain
}

\author{
Laxmaiah Manchikanti (D) - Rachana Vanaparthy · Sairam Atluri ·
}

Harsh Sachdeva $\cdot$ Alan D. Kaye · Joshua A. Hirsch

Received: August 14, 2020 / Accepted: February 8, 2021 / Published online: March 14, 2021

(C) The Author(s) 2021

\section{ABSTRACT}

The COVID-19 pandemic has affected the entire world and catapulted the United States into one of the deepest recessions in history. While this pandemic rages, the opioid crisis worsens. During this period, the pandemic has resulted in the decimation of most conventional medical services, including those of chronic pain management, with the exception of virtual care and telehealth. Many chronic pain patients have been impacted in numerous ways, with increases in

L. Manchikanti $(\bowtie)$

Pain Management Centers of America, Paducah, KY, USA

e-mail: drlm@thepainmd.com

L. Manchikanti

Anesthesiology and Perioperative Medicine,

University of Louisville, Louisville, KY, USA

L. Manchikanti

Department of Anesthesiology, School of Medicine, LSU Health Sciences Center, New Orleans, LA, USA

R. Vanaparthy

Oregon Health and Science University, Portland, OR, USA

S. Atluri

Tri-State Spine Care Institute, Cincinnati, OH, USA

H. Sachdeva

Pain Division and Fellowship Program, University of Cincinnati College of Medicine, Cincinnati, $\mathrm{OH}$, USA cardiovascular disease, mental health problems, cognitive dysfunction, and early death. The epidemic has also resulted in severe economic and physiological consequences for providers. Drug deaths in America, which fell for the first time in 25 years in 2018, rose to record numbers in 2019 and are continuing to climb, worsened by the coronavirus pandemic. The opioid epidemic was already resurfacing with a $5 \%$ increase in overall deaths from 2018; however, the preliminary data show that prescription opioid deaths continued to decline, while at the same time deaths due to fentanyl, methamphetamine, and cocaine

\section{A. D. Kaye}

Anesthesiology and Pharmacology, Toxicology, and Neurosciences, Pain Management Fellow Program Director, LSU School of Medicine, Shreveport, LA, USA

\section{A. D. Kaye}

Anesthesiology and Pharmacology, LSU School of Medicine, New Orleans, LA, USA

\section{A. D. Kaye}

Anesthesiology and Pharmacology, Tulane School of Medicine, New Orleans, LA, USA

\section{J. A. Hirsch}

Massachusetts General Hospital and Harvard Medical School, Boston, MA, USA 
climbed, with some reductions in heroin deaths. The health tracker data also showed that along with an almost $88 \%$ decline in elective surgeries, pain-related prescriptions declined $15.1 \%$. Despite increases in telehealth, outpatient services declined and only began returning towards normal at an extremely slow pace, accompanied by reduced productivity and increased practice costs. This review, therefore, emphasizes the devastating consequences of concurrent epidemics on chronic pain management and the need to develop best practice efforts to preserve access to treatment for chronic pain.

Keywords: Chronic pain; Concurrent epidemic; COVID-19; Epidemics; Interventional techniques; Opioid epidemic; Opioid use disorder

\section{Key Summary Points}

\section{Why carry out this study?}

The COVID-19 pandemic has led to a simultaneously deep and abrupt economic recession in the United States. While the opioid epidemic has not gone away, the management of chronic pain patients has been hampered by the restriction of interventional techniques and office visits. This has significantly affected chronic pain patient management and caused severe restrictions in non-opioid therapy. Further, opioid therapy has been allowed only in patients who are stable and do not require assessments or adherence monitoring.

Complicating the COVID-19 pandemic and undertreatment of chronic pain, the opioid crisis continues, with an increase in overdoses of $46 \%$ from the prior year as of May, and a $13 \%$ increase in overdose deaths. Most of these deaths are related to non-prescription opioids and stimulants, with prescription opioid deaths declining up to 2019. This review will explore the interplay of these concurrent epidemics.

\section{What was learned from this study?}

This review illustrates the substantial impact of multiple concurrent epidemics including COVID-19, opioids, and severely restricted access to chronic pain management.

The need for future actions to improve appropriate access to the management of chronic pain with physical therapy, interventional techniques, appropriate diagnostic modalities, and opioid therapy is highlighted.

\section{DIGITAL FEATURES}

This article is published with digital features, including a summary slide, to facilitate understanding of the article. To view digital features for this article go to https://doi.org/10.6084/ m9.figshare.13720828.

\section{INTRODUCTION}

While the entire world continues to suffer from the coronavirus disease 2019 (COVID-19) pandemic and the vast amount of resources spent on mitigation of the virus, it is exacerbated in the United States by the opioid epidemic [1-8]. Further, the pandemic is creating additional challenges by the delayed care of non-COVID19 disorders, including the ability of patients with pain to receive timely management, and compromising the treatment of opioid use disorder [9-11]. Numerous factors, including shelter-in-place recommendations, travel restrictions, and greater use of telemedicine, have made it necessary to ensure increased flexibility for patients with pain to obtain necessary medications and other treatments [4].

The convergence of concurrent emergencies has not only created a public health debacle but is exacerbating the national health care crisis due to the increased risk of COVID-19 in patients on high-dose opioids and those with 
opioid use disorder, as well as the restrictions in patient visits; add to this disrupted support systems and treatments increasing the risk for addiction and isolation increasing the risk for overdose deaths $[8,10,11]$.

The utilization of a multitude of health care services is down, sometimes quite dramatically [12]. Recent estimates by a health system tracker [12] have shown reductions as high as $86 \%$ in elective surgical volume overall, including interventional techniques administered for chronic pain, with reductions in pain-related drug prescriptions of $15.1 \%$. These factors, in conjunction with the psychosocial stressors of lockdown, along with exacerbation of multiple physical and psychological conditions, specifically those related to chronic pain, have in turn exacerbated the opioid epidemic, leading to increased levels of deaths and curtailing the treatment for opioid use disorder, with continued unavailability of non-opioid treatments for managing chronic pain [12-21].

The coronavirus pandemic catapulted the country into one of the deepest recessions in United States history. There is significant evidence that economic hardship is associated with poor health and can increase the risk of cardiovascular disease, mental health problems, cognitive dysfunction, and early death. Despite the negative consequences, the lockdown has saved lives [22]. Yakusheva et al. [22], with a team of health economists from US universities, reviewed the latest data and scientific research on the virus to evaluate the number of lives saved when public health measures remain in place. They also reviewed economic studies looking at deaths caused by past restrictions of economic activity to assess the number of lives that could be lost if those measures trigger an extended economic recession. They estimated that by the end of 2020, public health measures to mitigate COVID-19, including shelter-inplace orders, school and business closures, and social distancing and face mask recommendations, would save between 900,000 and 2.7 million lives in the United States. Further, they estimated that the economic downturn and loss of income from shelter-in-place measures and other restrictions on economic activity could contribute to between 50,400 and 323,000 deaths, based on an economic decline of $8-14 \%$. Public health experts tend to agree that the initial mitigation strategies utilizing lockdowns and gradual reopening, despite some inevitable resurgence, will save lives.

This article reviews the effect of concurrent public health emergencies colliding with COVID-19, the opioid epidemic, opioid abuse disorder, and finally, restrictions in access to chronic pain management. We also describe multiple adverse economic consequences resulting from enhanced audits, increased premiums leading to increased deductibles and copays, reduced reimbursements, a tsunami of regulations, and non-coverage policies resulting in reduced income $[12,13,16,18,22]$. Further, there has been an increased practice expense caused by having to maintain staff of 110-150\%. This has been necessary for COVID19 screening, testing, monitoring, quarantining, increased benefits levels, and enhanced expenses for personal protective equipment (PPE) of $600-1500 \%$ increase for patients and staff. However, even at this increased level of practice expenses and workload, caseloads continue to be only $50 \%[12,13,16,18,22]$.

This article is based on previously conducted studies and does not contain any studies with human participants or animals performed by any of the authors.

\section{IMPACT OF COVID-19 ON CHRONIC PAIN}

The impact of chronic pain on society is enormous, with consumption of health care resources, disability, and economic toll [12, 13, 16, 18, 22-27]. Multiple studies had shown an increasing impact of chronic pain prior to the COVID-19 pandemic. Dieleman et al. [23] showed that in 2016, low back and neck pain costs were the highest of any condition, with expenditures of $\$ 134.5$ billion, an increase of $44.4 \%$ from $\$ 87.6$ billion in 2013 . Multiple modalities of treatment are provided in managing chronic pain, including interventional techniques [24-34]. There is no agreement as to the best modality of treatment in managing chronic pain, with multiple 
discordant opinions based on individual preferences [26-36]. Among the nonsurgical modalities in managing chronic pain, interventional techniques, physical therapy, and opioids are commonly utilized treatments [24-37]. However, prior to the COVID-19 epidemic and all the ensuing issues, the utilization of interventional pain management techniques had been gradually declining since 2009, after extensive increases prior to 2009 [37]. Similarly, opioid prescriptions decreased 40\% from 2013 to 2019 in conjunction with declining prescription opioid deaths [38-43].

Chronic pain is not only disabling, but if left untreated, it may lead to serious consequences. The extent of untreated pain, specifically during the COVID-19 epidemic, may not yet be fully appreciated. It has been shown that patients with chronic pain who cannot obtain treatment face additional interference with their basic functioning, with $50 \%$ reporting that it leads to feelings of depression, while $35 \%$ report suicidal ideation [14]. In one of the studies [44], significant changes in pain intensity levels, emotional suffering and disability were reported with a wait time of 3 months. During the COVID-19 pandemic, the decimation of multiple health care services, specifically interventional techniques and elective surgeries, has been extensively described [12-22]. The only uninterrupted services were through telehealth for follow-up patients, without patient contact or monitoring [13, 17, 45]. Thus, delayed treatment may lead some pain patients to seek out alternate and possibly inappropriate or harmful treatments, such as elevated doses of nonsteroidal anti-inflammatory drugs, illicit drugs, or escalating opioid use [45]. Incidentally, many patients with chronic pain are also at high risk for COVID-19, as they can be elderly, those with chronic underlying diseases, those staying in nursing homes or assisted living, and those with limited access to care $[14,15,45]$. Since pain is the reason for $45 \%$ of visits to emergency departments [46], the influx of pain patients to emergency departments has overwhelmed some hospitals, ramped up the need for PPE independent of COVID-19 units, and exposed health care professionals to the risk of treating patients with unknown COVID status. With only emergency services being allowed during lockdown, it was difficult to manage patients, even with simple procedures such as epidural injections, facet joint nerve blocks, and radiofrequency neurotomy. which often would reduce untold suffering and health care costs. In fact, it has been observed that a new US health crisis looms as patients without COVID-19 delay their care $[9,13-20]$. The survey [9] showed that with multiple instances of unattended emergencies leading to serious complications during the pandemic, emergency department use dropped by $42 \%$ during the first 10 weeks of the pandemic despite a rise in patients presenting with symptoms of the coronavirus. Further, patients seeking care for myocardial infarctions dropped by $23 \%$ and strokes by $20 \%$. Thus, along with a multitude of conditions, the diagnosis of chronic pain and subsequent treatment has been delayed.

Consequences of inadequate treatment include the significant psychosocial impact, increasing disability, and prescription and illicit drug abuse. Ironically, even after opening in multiple phases it appears with prioritization of elective surgery, interventional procedures have been delayed [14-16]. Health and economic impact on health services was relatively flat in the first quarter of 2020, with small increases of $5.9 \%$ for nursing homes, $3.9 \%$ for physician offices, and $1.1 \%$ for outpatient care centers, with a decline in medical labs (2.7\%) and in hospitals (4.1\%) [12]. However, spending on health services dropped sharply in March and April 2020 compared to the previous year according to personal consumption expenditure data from the Bureau of Economic Analysis (BEA) [16]. Across all health care services, which does not include pharmaceutical drugs, expenditures were down 38\% in April 2020 compared to April 2019. These drops were considered to be unprecedented, and it was estimated that based on the drops in April, a reduction by almost $\$ 1$ trillion would be seen over a 12 -month period. In fact, the drop in health spending was particularly sharp for dental services (61\%) and physician offices $(45 \%)$ despite increasing telehealth services, even though telehealth services increased 300-fold from March 15, 2019 to April 14, 2020. Almost half of adult patient 
appointments were managed with telemedicine instead of in-office from mid-March and midApril, across all age groups. Notably, an overwhelming majority of the services were provided by telehealth and phone only [16-18, 20]. Consequently, many hospitals lost revenues in March, with reduced spending by insurers, and sharp drops in utilization in April 2020 relative to the previous year.

More importantly, elective surgeries declined as much as $88 \%$ in April, then returned towards normal with a $60 \%$ decline in May (Fig. 1). In addition, the total number of filled prescriptions was also reduced by $15.1 \%$ compared with the previous year, as shown in Fig. $2[12,47]$. Further, much of the drop in prescription fills was among pain medications, oncological, hypertension, and lipid regulators as shown in Fig. 2 [12, 47]. Even though multiple reasons have been established for this drop, including 90-day prescriptions, and despite the rebound in late April, overall there was a significant reduction in prescriptions, which may promote opioid abuse and opioid-related deaths.

Additional confounders for interventional factors include economic losses resulting from continued partial lockdowns, enhanced audits, reduced reimbursement due to increased premiums, increasing deductibles and copays, and inability to collect funds from patients $[16,20]$. There have also been extensive rate cuts and denials of service and excessive practice expenses causing substantial economic impact, with reduced income in addition to necessary increases in levels of staffing for only a 50\% caseload while at $110-150 \%$ staff expenses, and increased expenses for PPE of 600-1500\% [16, 20].

\section{OPIOID EPIDEMIC}

The importance of opioid use and abuse and their consequences have been well-described in multiple manuscripts [24-26, 34, 39-41, 48-50]. The American Society of Interventional Pain Physicians (ASIPP) [48] and the Centers for Disease Control and Prevention (CDC) [50] have developed extensive guidance on responsible, safe, and effective prescribing of opioids for chronic non-cancer pain. It is well recognized that the growing epidemic of the medical use and abuse of opioid analgesics and other controlled substances is closely associated with economic burden and fatalities in the United States and many other developed countries, including Australia, Canada, and the United Kingdom, with Germany being a notable exception, as shown in Fig. 3 [49]. Fortunately, the US drug overdose data for drug-related deaths from 2018 show an arrest in the escalation and a dip in the curve towards reductions $[34,39,40,50-52]$. The report also revealed a decline in overdose death rates of $14.5 \%$ for prescription opioids and 3\% for heroin from 2017 (Fig. 4), and prescriptions decreased by over $40 \%$ from 2013 to 2019, as shown in Fig. 5 $[42,43]$. Data also showed that US prescribed opioid volume declined $17 \%$ in 2018-the largest single-year drop ever recorded [43]. Even then, the United States has experienced more deaths related to opioids than any other country. At the same time, even prior to COVID-19, the undertreatment of pain and the negative outcomes of unbalanced opioid policies with impaired access have been extensively described and pose significant individual and public health problems [48-51]. Manchikanti et al. [34] described various issues related to the opioid epidemic and clearly pointed to the tragic failures of current systems to control opioid misuse. Federal and state spending was increased to control the opioid epidemic [24, 52].

\section{PSYCHOSOCIAL IMPACT OF COVID-19}

Multiple issues related to the opioid epidemic start with the overall psychosocial impact on society. At present, with COVID-19, the uncertainty of being corona positive, experiencing the burden of being quarantined, inadequate health care services, and the effect on health care providers come to the forefront $[2,21,53-55]$. Along with the disease itself, multiplied by forced quarantine to combat COVID-19 and by nationwide lockdowns can produce acute panic, anxiety, obsessive behavior, hoarding, paranoia, depression, and post- 


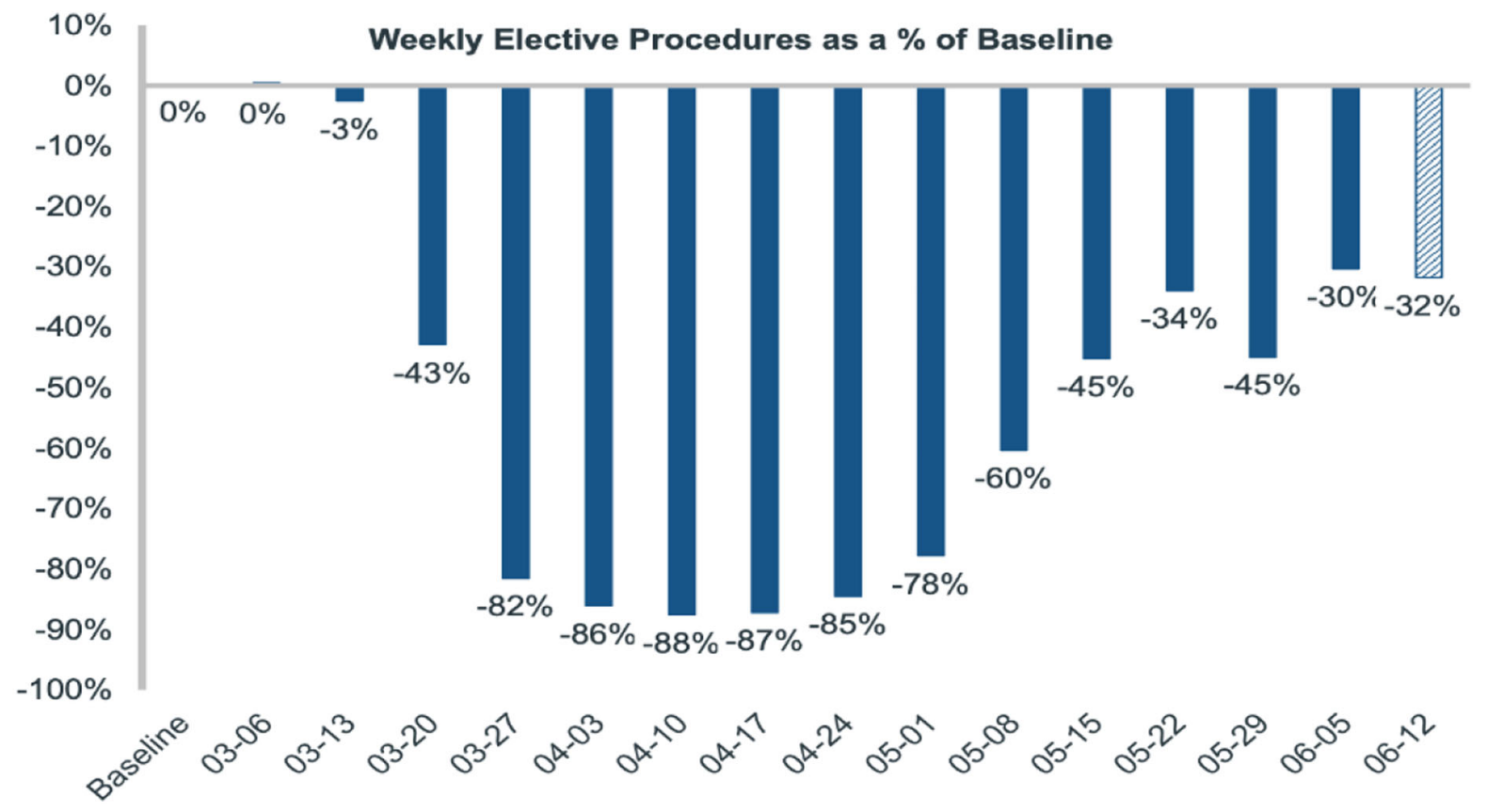

Data for latest week date controlled against prior periods; estimates have been applied to reflect anticipated late-adjudicated claims based on historical rates

Fig. 1 Weekly elective procedures as a \% of baseline. Source: IQVIA: Medical Claims Data Analysis, 2020; Baseline $=$ Average of procedures for period W/E 1/10/ $2020-2 / 28 / 2020$. Elective procedures based on IQVIA

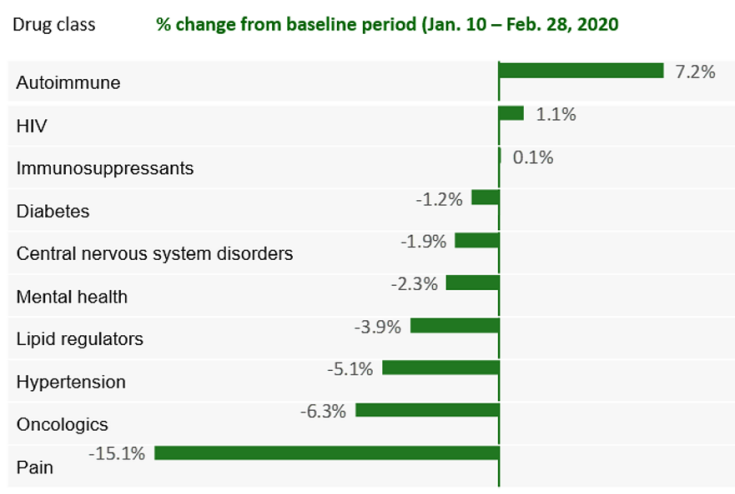

Fig. 2 Percent change in filled prescriptions for selected drug classes, week ending May 1, 2020 vs. baseline and prior week. Source: IQVIA National Prescription Audit; Market definitions courtesy of IQVIA Institute for Human Data Science [47]

traumatic stress disorder (PTSD) in the long run. These have also been fueled by an infodemic custom analysis [47]. Estimated amounts for latest 2 weeks applied based on likely claims still to be received due to data latency or claim processing delays

Fig. 3 The deadly toll of America's opioid crisis. Source: Richter F. The deadly toll of America's opioid crisis. Statista June 26, 2020. Accessed 7/14/2020. https://www. statista.com/chart/22118/drug-related-deaths-per-millionpeople/ [49] 


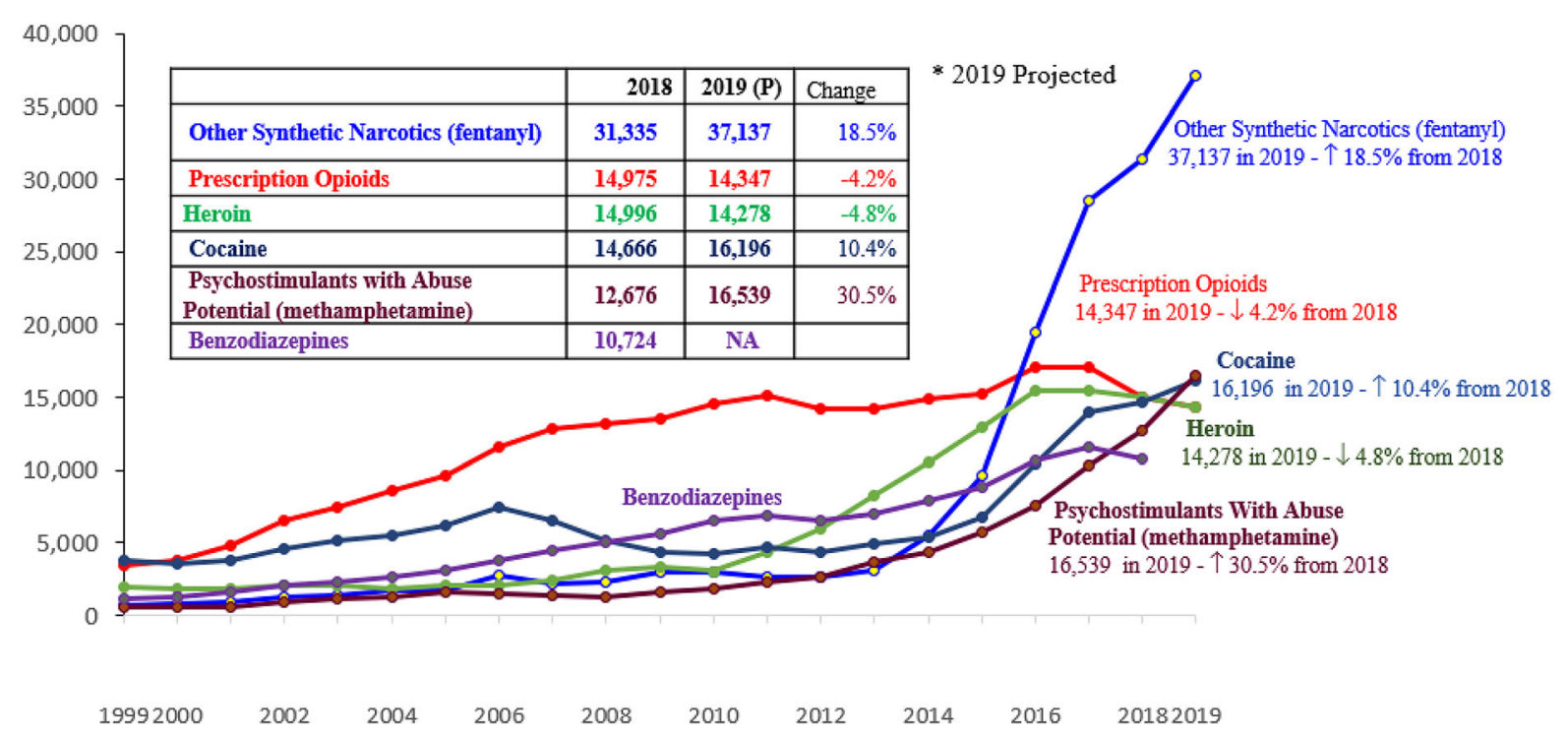

Fig. 4 Number of opioid overdose deaths by category, 1999 to 2019. Source(s): For 1999-2018: National Institute on Drug Abuse. Overdose death rates. May 7, 2020 https://www.drugabuse.gov/relatedtopics/trendsstatistics/ overdose-death-rates [38, 40]. For 2019:

spread via different platforms on social media. Further, frontline health care workers are at higher risk of contracting the disease, as well as experiencing adverse psychological outcomes in the form of burnout, anxiety, fear of transmitting infection, feelings of incompatibility, depression, increased substance dependence, and PTSD [2, 11, 21, 53-60]. Children may be affected more so with disruption of their usual lifestyle, leading to mental distress [61, 62]. Older people, their caregivers, psychiatric patients, and marginalized communities are affected by this pandemic in different ways and need special attention [63-66]. The psychosocial response of frontline workers during the pandemic is complex, and further, it is not completely understood [67-69]. Studies regarding the 2003 severe acute respiratory syndrome (SARS) outbreak from Canada, Taiwan, and Hong Kong have discussed how the battle against SARS led to huge psychosocial morbidity among frontline health care providers $[13,21]$. Even 3 years after of the SARS outbreak in 2003, a significant number of related hospital
Ahmad FB, Rossen LM, Sutton P. Provisional drug overdose death counts. National Center for Health Statistics. 2020 [41]. https://www.cdc.gov/nchs/nvss/vsrr/drugoverdose-data.htm

workers in Beijing, China experienced some PTSD [21].

Similarly, unavoidable stress, fear, and anxiety about poorly known contagious disease outbreaks, like COVID-19, can be profound among the higher risk groups, such as health care providers and other frontline workers including bankers, police officers, and the armed forces. It is also shown that being exposed to COVID-19 cases in hospitals, being quarantined, the death or illness of a relative or friend from COVID-19, and heightened selfperception of the danger of the lethality of the virus can all negatively impact the mental wellbeing of health care workers [21]. Various types of psychological stressful events associated with vicarious traumatization among the medical and nursing staff have been reported during the spread and control of the COVID-19 pandemic in China, which is seen in the United States at present. In addition, multiple issues related to lack of PPE, deaths, and the inability to see members of the family may cause additional problems. Multiple authorities have shown the significant risk of burnout, depression, anxiety, 


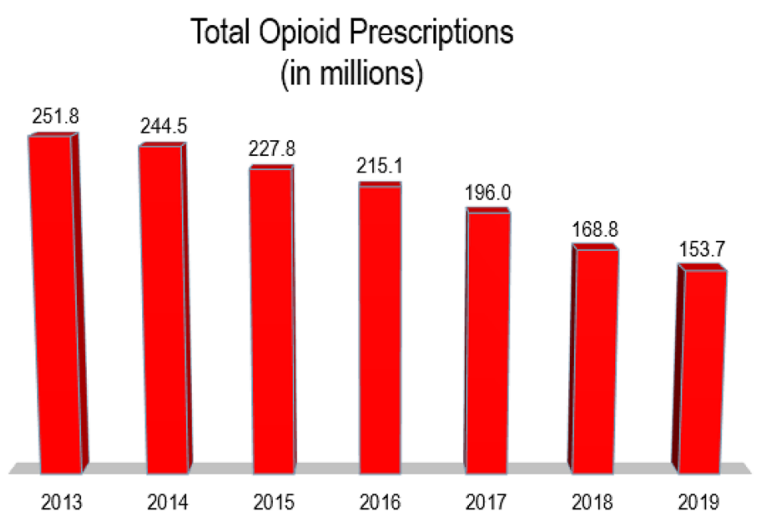

Fig. 5 Total opioid prescriptions in the United States in millions, 2014-2019. Source(s): American Medical Association. Opioid Task Force 2020 Progress Report. Physicians' Progress Toward Ending the Nation's drug overdose and death epidemic. Accessed 7/27/2020. https://www. ama-assn.org/system/files/2020-07/opioid-task-forceprogress-report.pdf [42]. IQVIA ${ }^{\mathrm{TM}}$ Institute for Human Data Science Releases 2019 Medicines Report on U.S. Drug Consumption; U.S. Rx Opioid Volume Declined 17\% in 2018 - Largest Single-Year Drop Ever Recorded. Accessed 7/27/2020. https://www.iqvia.com/newsroom/ 2019/05/iqvia-institute-for-human-data-science-releases2019-medicines-report-on-us-drug-consumption-us-rx-o [43]

PTSD, and compassion fatigue as some of the major aspects and difficulties that need to be addressed [13, 55].

Jha et al. [13] conducted a survey of interventional pain physicians evaluating burnout in reference to the COVID-19 pandemic. This survey showed that $98 \%$ of physician practices were affected, whereas $91 \%$ of physicians felt it had a significant impact and $78 \%$ were very concerned. Further, the survey also showed 67\% of physicians responding that in-house billing was responsible for their increased level of burnout, whereas $73 \%$ responded that electronic medical records were one of the causes. Overall, $60 \%$ had a negative opinion about the future of their practice, whereas $66 \%$ were negative about the entire health care industry as shown in Fig. 6.

\section{COVID-19 AND OPIOID USE DISORDER AND ADDICTION}

Dubey et al. [54] have described COVID-19 and addiction. They have observed that people with substance abuse disorders are at heightened risk for pulmonary infections related to:

1. Substance abuse-related preexisting cardiopulmonary comorbidities

2. Mucociliary dysfunction

3. Compromised immunity

4. Altered health-seeking behavior and inadequate access to health care delivery

5. Failure of rehabilitation strategies due to social distancing

6. Housing instability

Individuals with preexisting morbid respiratory and cardiac pathologies, including chronic obstructive pulmonary and cardiovascular diseases, are established as a high-risk population for acquiring novel severe acute respiratory system coronavirus, which leads to greater mortality [70-76]. Related to the significant association of cardiorespiratory and metabolic ailments in patients suffering with substance use disorders, probability is high for them to be at heightened risk for COVID-19 [72]. Smoking has also been found to be an adverse prognostic indicator in COVID-19 [73-76]. Specific risk factors related to COVID-19 are increased expression of type 2 angiotensin-converting enzyme (ACE2) among smokers [72, 77], in addition to the traditional risks generally imposed by smoking on cardiopulmonary health [78]. Moreover, nicotinic pathway-mediated overexpression of ACE2, the putative receptor for SARS-CoV-2, might be associated with increased virion entry [72, 77, 79-82]. However, smoking as an independent risk factor has not been established [83]. Multiple negative effects of other inhalation modalities with electronic cigarettes have also been described [84]. Further, similar health risks are imposed by alcohol consumption, even though there is a lack of systematic data regarding alcohol consumption and COVID-19 risk [85].

Opioid therapy has been considered as a risk factor for fatal outcome, with overdose causing 


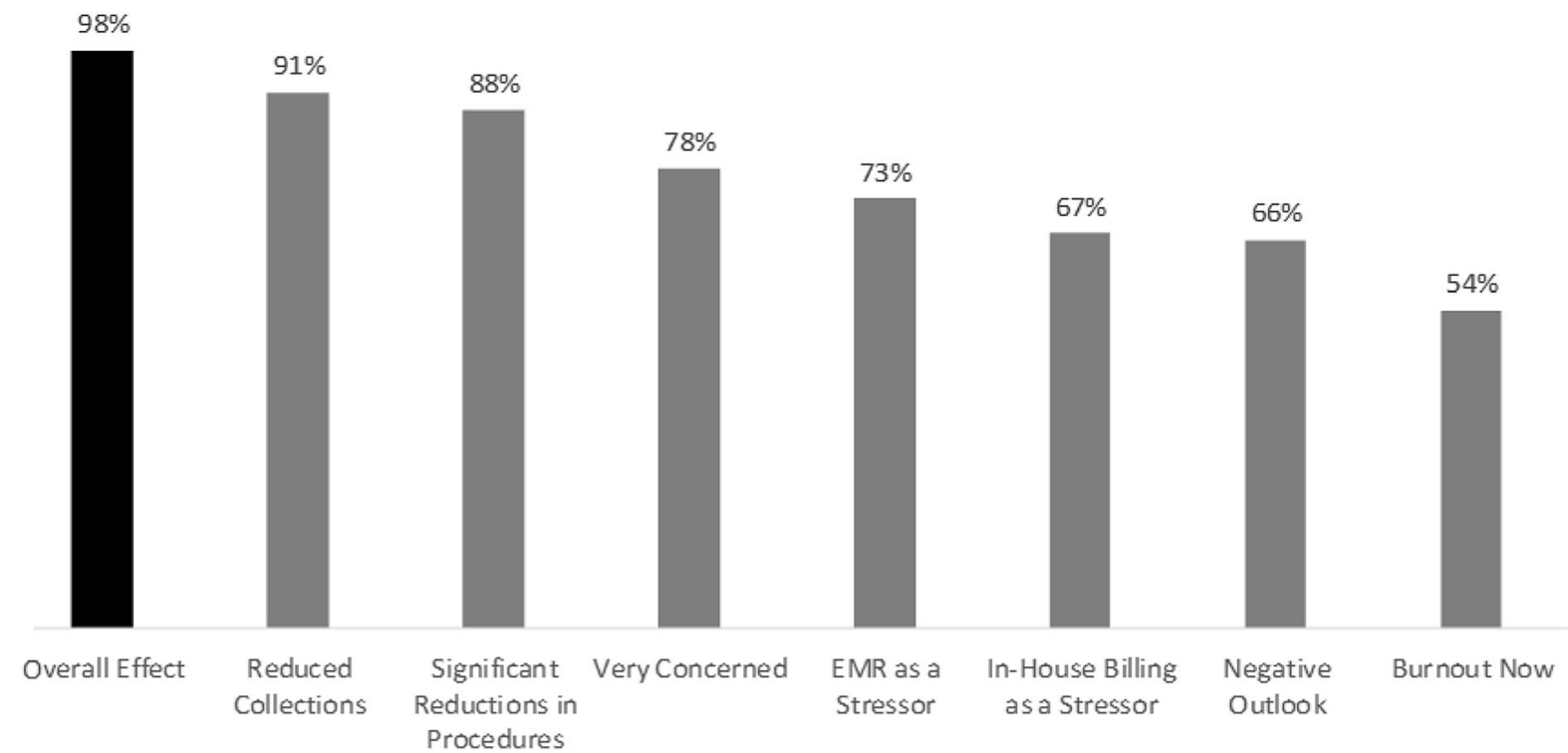

Fig. 6 Results of burnout survey illustrating multiple adverse effects of COVID-19 pandemic on IPM practices. Reproduced with permission from Jha et al. The effect of

respiratory depression and hypoxemia, which in turn lead to cardiopulmonary and neurological complications and worsened outcomes of COVID-19 [2]. Methamphetamine can cause lung injury, pulmonary hypertension, and cardiomyopathy, negatively affecting the outcomes of COVID-19 among methamphetamine users [86].

Multiple behaviors, other than self-risk, associated with substance abuse provide a recipe for community spread of the virus with SARSCoV-2-laden particles drifting through mephitic vaping and wafting smoke [54, 87], and repetitive spitting habits [88]. Further, high-risk behaviors such as sharing of cigarettes, alcohol, and needles between peers increase the chance of outbreak [89]. Considering alcohol shops as essential services may have contributed not only to further spread due to disruption of physical distancing [90], but also by the increased consumption of alcohol, shown to be approximately $55 \%$.

Dubey et al. [54] have described widespread concern that physical and social functioning, as well as mental well-being of the substance users and addicts will be abysmally affected by the COVID-19 crisis. Acute and chronic stressors
COVID-19 on interventional pain management practices: A physician burnout survey. Pain Physician 2020; 23:S271-S282 [13]

have been attributed to the inception and protraction of many substance use disorders among the general public. Serotonergic modulation of the dopaminergic pathways leads to reduced activation of the mesolimbic reward circuit of the brain in people with depression. Consequently, addictive substances such as opioids, alcohol, and smoking produce prolific activation of the reward system bringing temporary pleasure to them. In addition, alcoholic beverages have been shown to result in neuronal adaptations in the stress and reward pathways and flare-ups in the neuroendocrine responses and stress reactivity, which in turn aggravate alcohol related cravings when stressful situations arise [91, 92]. The unique circumstances created by the COVID-19 pandemic in terms of chronic social isolation, physical and social distancing, the sustained lockdown across the country, the inability to obtain appropriate health care, shutdown of health care facilities until they reopened and then closing again will result in various undesirable outcomes with respect to health and well-being [21]. Despair due to fear of contracting the infection, distress due to vulnerability, working from home, and depression leading to other psychological 
abnormalities may force individuals to take refuge in addictive substances, often whichever is cheapest and/or most readily available, to allay their negative feelings. This can potentially trigger the development of substance use disorder in high-risk groups and create a spike in the incidence of substance use disorder among the general population as well [93-95].

With increased levels of threat of infection to persons with opioid use disorders, together with pre-existing medical and psychiatric comorbidities, there is a serious risk that system-level gains in expanding access to medication for opioid use disorder, conducting critical research, and exacting legal reparations against opioid manufacturers will be reversed [2].

\section{CONCURRENT EPIDEMICS OF COVID-19 AND OPIOIDS}

Chronic pain itself may be a risk factor due to immunosuppression and inability to fight against COVID-19 once contracted, added to the issues related to psychosocial impact and addiction [21, 22]. Multiple manuscripts have been published describing these issues; however, the focus has been mostly on opioid use disorder. The adverse consequences of lockdown and the inability to receive appropriate treatment, as described earlier, are of paramount importance in managing patients with chronic pain.

In the shadow of the COVID-19 pandemic, the opioid epidemic once again is showing a resurgence, with record overdose deaths in 2020 [6-8]. Opioid-related deaths, which fell for the first time in 25 years in 2018, rose to record numbers in 2019 and are continuing to climb, a resurgence that is not only complicated, but worsened, by the coronavirus pandemic. Based on the preliminary data from the CDC, nearly 72,000 Americans died from drug overdoses in 2019, an increase of 5\% from 2018 (Fig. 4). Even more ominous are the preliminary figures available for 2020, which appear to be worse. Drug deaths rose an average of $13 \%$ through June in 2020 over the prior year. What is even more worrisome is that if this trend continues for the rest of the year, it will be the sharpest increase in annual drug deaths since 2016, when synthetic opioids, dominated by fentanyl, made significant inroads in the county's illicit drug supply.

The 2018 decline was largely explained by reductions in deaths from prescription opioid medications. This trend continues, with prescription opioid deaths declining to 12,068 in 2019 compared to 14,975 in 2018 , a $4.2 \%$ decrease from 2018 to 2019. However, deaths related to cocaine surged to 16,196 (up 10.4\%), while those related to fentanyl deaths increased to 37,137 (up 18.5\%) and deaths related to methamphetamine to16539 (up 30.5\%). Drugrelated deaths have seen the highest increases from 2009 to 2020 in the states of Delaware, Washington, Wisconsin, Colorado, Rhode Island, Iowa, Vermont, Louisiana, California, Minnesota, Texas, New Jersey, Illinois, and Florida, in descending order, as shown in Fig. 7.

The US drug overdose data for drug-related deaths reported by the CDC's Health Alert Network (HAN) health advisory (38) showed a significant increase in fatal drug overdoses across the United States, driven by synthetic opioids, before and during the COVID-19 pandemic. The report, based on recent provisional data, showed that approximately 81,230 drug overdose deaths occurred in the USA in the 12 months ending May 2020, as shown in Fig. 8. Consequently, the worsening of the drug overdose epidemic in the United States not only has shown a resurgence, but is also the largest number of drug overdoses for a 12-month period ever recorded. The number of overdose deaths increased $18.2 \%$ for the 12 months from June 2019 to May 2020. Further, increases in drug overdose deaths ranged above $20 \%$ in 25 states and the District of Columbia, $10-19 \%$ in 11 states and New York City, and 0-9\% in 10 states. Overdose deaths decreased in only four states.

\section{CONTROLLING THE OPIOID EPIDEMIC}

There are several broad schools of thought about the opioid epidemic. The supporters of the theory that too many opioids are provided 


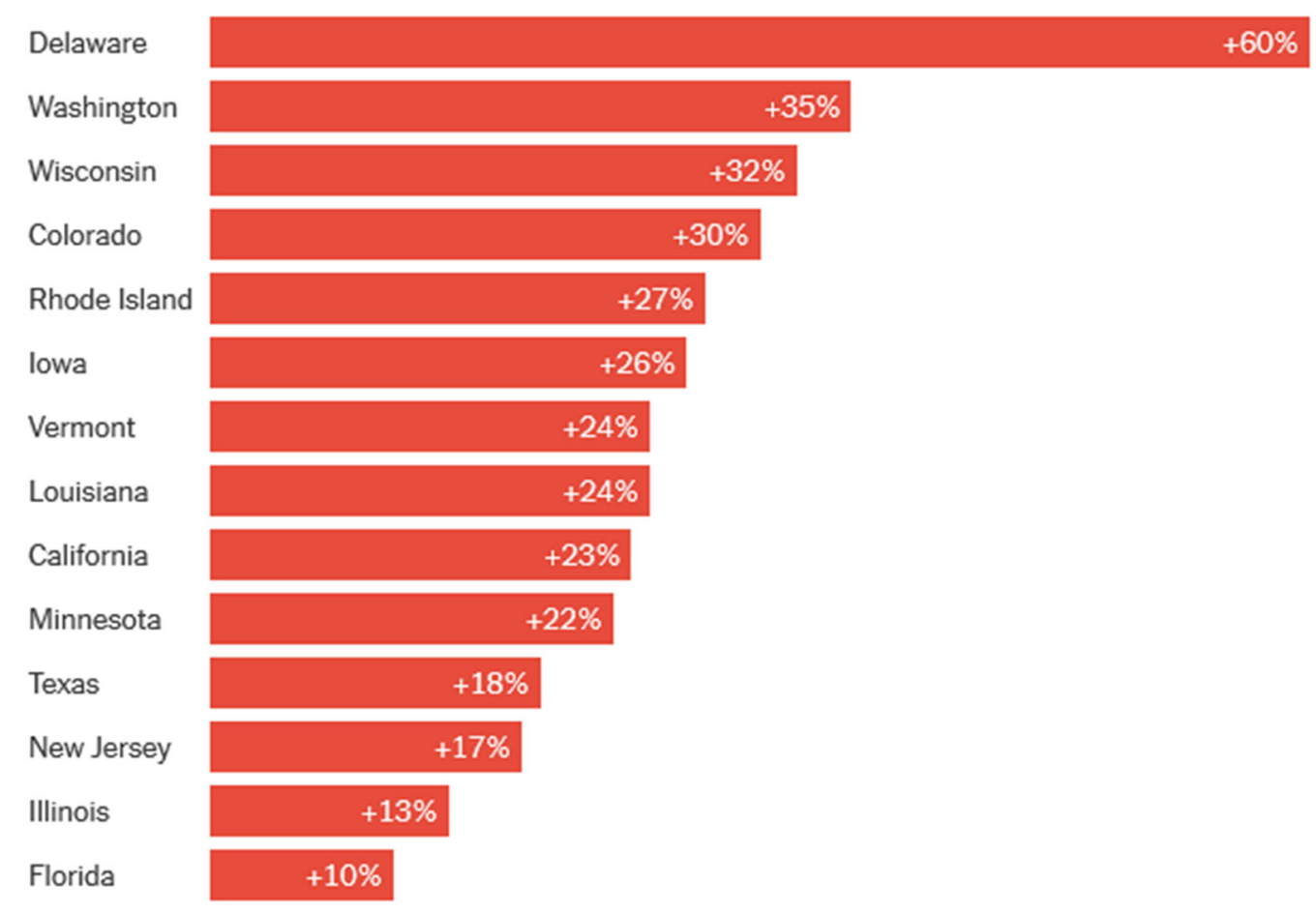

Fig. 7 Drug-related deaths have risen in 2020 in states across the country (increase in drug-related deaths from 2019 through the first portion of 2020). All data are provisional. Definitions of what counts as a drug-related death vary by state. Data for Arizona, California, Florida,

immediately (too soon) state that controlling opioid prescriptions will eliminate the opioid epidemic [96]. However, the facts show differently, as prescription opioid overdose deaths are declining, along with opioid prescriptions and doses, as a result of existing guidance, rules and regulations $[43,50]$. In contrast, the proponents of increased supply of opioids many stakeholders posit that the opioid supply should be reduced, along with strict regulations. A third category is that the crisis is fundamentally fueled by economic and social issues, its etiology closely linked to the role of opioids as a refuge from physical and psychological trauma, concentrated disadvantage, isolation and hopelessness. It is generally agreed that simplistic measures to cut access to opioids offer illusory solutions to a multidimensional societal challenge. Increasing the opioid supply and prescriptions will not solve the problem. We have to resolve the issue of the crisis trajectory
Minnesota, Tennessee, Texas, Washington, and Wisconsin include only a subset of counties within each state. Source: State and local health departments, coroners and medical examiners

through the intertwined use of opioid analgesics, heroin and fentanyl analogs, and engaging in structural determinants to address this formidable public health emergency [5]. While we sort out the differences coming out of this economic and health care recession, certain measures must be initiated and implemented immediately. Some of these measures have been recommended in the past.

\section{CURTAILING OVERDOSE DEATHS}

The public, administration, and medical community are gravely concerned by the increasing levels of deaths. Appropriate monitoring and interruption of the illicit drug supply must be continued or reinforced.

Risk factors must be identified and managed proactively. 


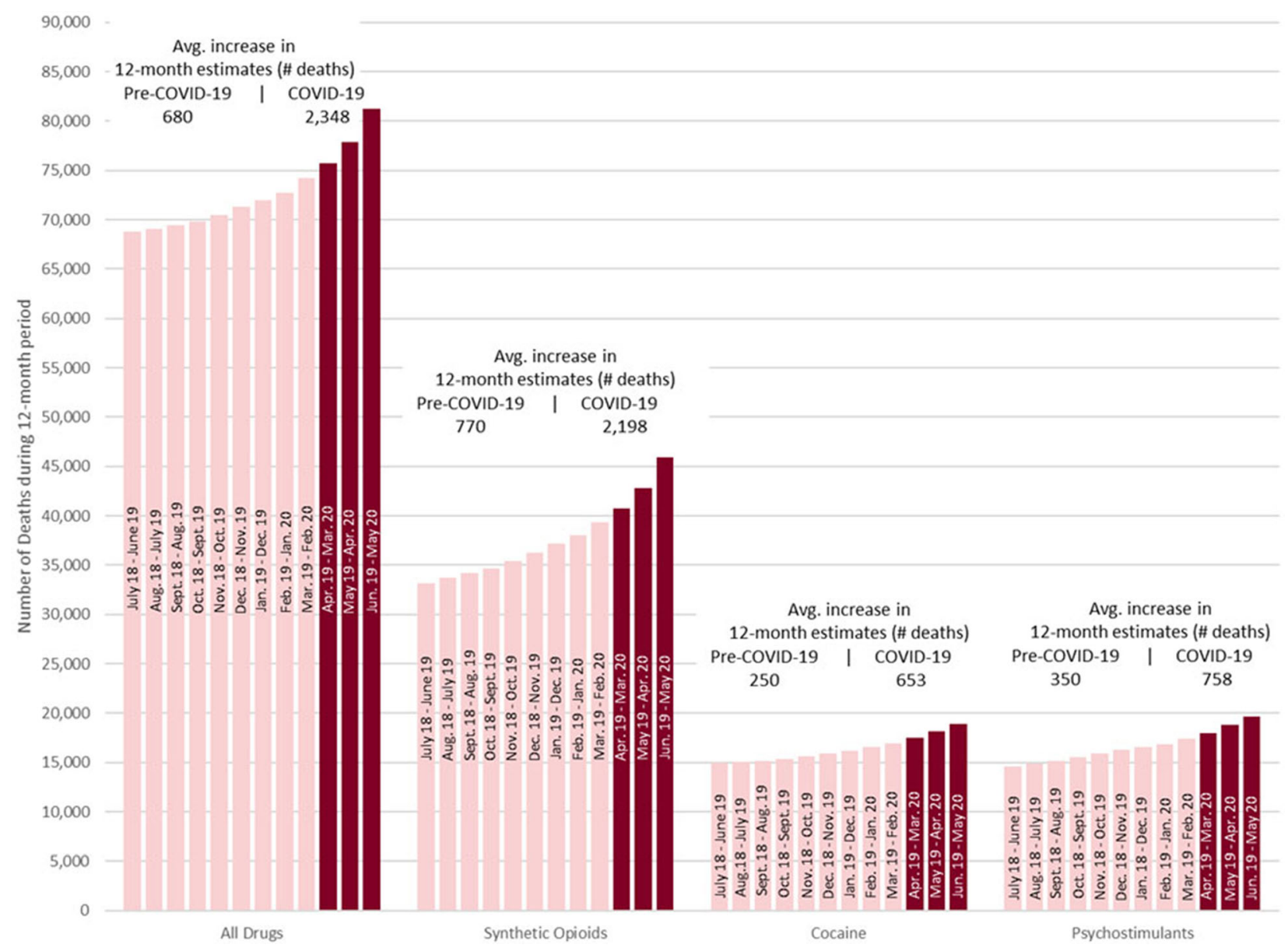

Fig. 8 Dramatic growth in overdoses during pandemic

\section{Opioid Use Disorder}

While buprenorphine may be continued with telehealth or telephone only services, especially for Medicare patients and others, through this public health emergency, all insurers and payers should allow for increasing flexibility for treating substance abuse disorder with buprenorphine.

\section{Opioids for Pain}

Because of the unavailability of elective surgeries and other procedures, opioid usage may actually increase rather than decrease at the present time. There should be a nationwide effort to address barriers to the refilling and prescribing of controlled substances for patients in pain during the pandemic. They should consider following the Drug Enforcement Administration (DEA) guidance for opioid prescriptions (https://www.deadiversion.usdoj. gov/GDP/(DEA-DC-023)(DEA075)Decision_ Tree_(Final)_33120_2007.pdf).

\section{LIMITATIONS}

Limitations of this manuscript include the evolving role of the concurrent epidemics of both COVID-19 and opioids, with continued devastating effects. The literature lags behind the dynamics of these concurrent epidemics. As further information is published and statistics are available, a multitude of issues will be resolved, and the effects of COVID-19 and opioid epidemics will become clear. 


\section{CONCLUSION}

In addition to major suffering from COVID-19 and the accompanying opioid epidemic, with the numerous consequences of lockdown and decimation of surgical and procedural services, patients with chronic pain and opioid disorders have suffered substantially related to limited access to treatment. At the same time, the opioid epidemic, which had seen a reduction in 2018 related to reductions in prescription opioid deaths, suddenly started showing increases in 2019 and escalated even further in 2020 thus far, with overdoses and overdose-related deaths of 5\% in 2019 and, on average, 13\% in 2020, while overdose increases were as high as $46 \%$ in May. Fortunately, prescription opioid-related deaths continue to decline, but unfortunately, deaths due to illicit fentanyl, methamphetamine and cocaine continue to escalate. Even after partial reopening, patients continue to suffer due to limited appointments, increased risk of coronavirus in certain segments of the population who also need opioid therapy, and finally the fear factor of acquiring COVID-19.

It is essential to formulate appropriate principles to provide appropriate opioid therapy and control the opioid epidemic without curbing access to therapeutic opioids and treatment of substance use disorders.

\section{ACKNOWLEDGEMENTS}

Funding. No funding or sponsorship was received for preparation or publication of this article.

Authorship. All named authors meet the International Committee of Medical Journal Editors (ICMJE) criteria for authorship for this article, take responsibility for the integrity of the work as a whole, and have given their approval for this version to be published.

Disclosures. Laxmaiah Manchikanti, Rachana Vanaparthy, Sairam Atluri, and Harsh Sachdeva have nothing to disclose. Joshua Hirsch is a consultant for Medtronic. Alan David Kaye is a member of the journal's Editorial Board and a speaker for Merck.

Compliance with Ethics Guidelines. This article is based on previously conducted studies and does not contain any studies with human participants or animals performed by any of the authors.

Open Access. This article is licensed under a Creative Commons Attribution-NonCommercial 4.0 International License, which permits any non-commercial use, sharing, adaptation, distribution and reproduction in any medium or format, as long as you give appropriate credit to the original author(s) and the source, provide a link to the Creative Commons licence, and indicate if changes were made. The images or other third party material in this article are included in the article's Creative Commons licence, unless indicated otherwise in a credit line to the material. If material is not included in the article's Creative Commons licence and your intended use is not permitted by statutory regulation or exceeds the permitted use, you will need to obtain permission directly from the copyright holder. To view a copy of this licence, visit http://creativecommons.org/licenses/by$\mathrm{nc} / 4.0 /$.

\section{REFERENCES}

1. Girion L, Levine D, Respaut R. Special report: COVID deepens the other opioid crisis - a shortage of hospital painkillers. Health News, June 9. 2020. https://www.reuters.com/article/us-healthcoronavirus-opioids-specialrep-idUSKBN23G1GM. Accessed 10 Jul 2020.

2. Becker WC, Fiellin DA. When epidemics collide: coronavirus disease 2019 (COVID-19) and the opioid crisis. Ann Intern Med. 2020;173:59-60.

3. American Medical Association. Issue brief: reports of increases in opioid-related overdose and other concerns during COVID pandemic. Updated June 30, 2020. https://www.ama-assn.org/system/files/ 2020-07/issue-brief-increases-in-opioid-relatedoverdose.pdf. Accessed 10 Jul 2020. 
4. American Medical Association. Issue brief: reducing barriers to vital pain medication during the COVID19 pandemic. 2020. https://www.ama-assn.org/ system/files/2020-05/issue-brief-reducing-barriersvital-pain-medication.pdf. Accessed 10 Jul 2020.

5. Dasgupta N, Beletsky L, Ciccarone D. Opioid crisis: no easy fix to its social and economic determinants. Am J Public Health. 2018;108:182-6.

6. Levitz E. U.S. drug overdose deaths hit record high in 2019. Intelligencer, July 15. 2020. Accessed 20 Jul 2020. https://nymag.com/intelligencer/2020/07/ drug-overdose-deaths-opioids-2019-2020coronavirus.html. Accessed 20 Jul 2020.

7. Katz J, Goodnough A, Sanger-Katz M. In shadow of pandemic, U.S. drug overdose deaths resurge to record. The New York Times, July 15. 2020. https:// www.nytimes.com/interactive/2020/07/15/upshot/ drug-overdose-deaths.html. Accessed 20 Jul 2020.

8. Ingersoll A. COVID-19 cited in spike of opioid overdoses. Investigative Post, May 21. 2020. https:// www.investigativepost.org/2020/05/21/covid-19cited-in-spike-of-opioid-overdoses/. Accessed $10 \mathrm{Jul}$ 2020.

9. Bernstein S. New US health crisis looms as patients without COVID-19 delay care. Reuters, July 13. 2020. https://www.reuters.com/article/us-healthcoronavirus-usa-care-idUSKCN24E143. Accessed 20 Jul 2020.

10. Grinspoon P. A tale of two epidemics: When COVID-19 and opioid addiction collide. Harvard Health Publishing, April 20. 2020. https://www. health.harvard.edu/blog/a-tale-of-two-epidemicswhen-covid-19-and-opioid-addiction-collide2020042019569. Accessed 10 Jul 2020.

11. Volkow N. COVID-19: Potential implications for individuals with substance use disorders. National Institute on Drug Abuse, April 6. 2020. https:// www.drugabuse.gov/about-nida/noras-blog/2020/ 04/covid-19-potential-implications-individualssubstance-use-disorders. Accessed 10 Jul 2020.

12. Cox C, Kamal R, McDermott D. How have healthcare utilization and spending changed so far during the coronavirus pandemic? Health System Tracker, May 29. 2020. https://www.healthsystemtracker. org/chart-collection/how-have-healthcareutilization-and-spending-changed-so-far-duringthe-coronavirus-pandemic/\#item-start. Accessed 10 Jul 2020.

13. Jha SS, Shah S, Calderon MD, Soin A, Manchikanti L. The effect of COVID-19 on interventional pain management practices: a physician burnout survey. Pain Phys. 2020;23:S271-82.
14. Gharibo C, Sharma A, Soin A, et al. Triaging interventional pain procedures during COVID-19 or related elective surgery restrictions: evidence-informed guidance from the American Society of Interventional Pain Physicians (ASIPP). Pain Phys. 2020;23:S183-2204.

15. Shah S, Diwan S, Soin A, et al. Evidence-based risk mitigation and stratification during covid-19 for return to interventional pain practice: American Society of Interventional Pain Physicians (ASIPP) Guidelines. Pain Phys. 2020;23:S161-82.

16. Kaye AD, Manchikanti L. COVID-19 special issue editorial. Pain Phys. 2020;23:S159-60.

17. Wahezi SE, Duerte RA, Yerra S, et al. Telemedicine during COVID-19 and beyond: a practical guide and best practices multidisciplinary approach for the orthopedic and neurologic pain physical examination. Pain Phys. 2020;23:S205-38.

18. Gharaei H, Diwan S. COVID-19 pandemic: Implications on interventional pain practice: a narrative review. Pain Phys. 2020;23:S311-8.

19. Soin A, Vuppala S, Surfield G, et al. Ohio response to COVID-19 and its impact on interventional pain management practices. Pain Phys. 2020;23: S439-48.

20. American Society of Interventional Pain Physicians (ASIPP) Fact Sheet 2020. A Perfect Storm: The Concurrent Public Health Emergencies of COVID19, Opioid Epidemic and a Tsunami of Deleterious Payer Policies. 2020. http://www.asipp.org//Links/ Attachment $\% 201 \% 20-\% 20$ A\%20Perfect $\%$ 20Storm $\% 20-\% 20$ Concurrent $\% 20$ Health\% 20Public\%20Health\%20Emergencies\%20Fact $\%$ 20Sheet.pdf. Accessed 30 Sep 2020.

21. Dubey S, Biswas P, Ghosh R, et al. Psychosocial impact of COVID-19. Diabetes Metab Syndr. 2020;14:779-88.

22. Yakusheva O, van den Broek-Altenburg EV, Brekke $\mathrm{G}$, Atherly A. The cure is not worse than the disease-a humanitarian perspective. SSRN, July 10. 2020 . https://papers.ssrn.com/sol3/papers. cfm?abstract_id=3638575. Accessed 14 Jul 2020.

23. Dieleman JL, Cao J, Chapin A, et al. US health care spending by payer and health condition, 1996-2016. JAMA. 2020;323:863-84.

24. Manchikanti L, Kaye AD, Soin A, et al. Comprehensive evidence-based guidelines for facet joint interventions in the management of chronic spinal pain: American Society of Interventional Pain Physicians (ASIPP) guidelines. Pain Phys. 2020;23: S1-127. 
25. Navani A, Manchikanti L, Albers SL, et al. Responsible, safe, and effective use of biologics in management of low back pain: American Society of Interventional Pain Physicians' guidelines. Pain Phys. 2019;22:S1-74.

26. Manchikanti L, Singh V, Kaye AD, Hirsch JA. Lessons for better pain management in the future: Learning from the past. Pain Ther. 2020 (Epub ahead of print).

27. Lee JH, Shin KS, Park SJ, et al. Comparison of clinical efficacy between transforaminal and interlaminar epidural injections in lumbosacral disc herniation: a systematic review and meta-analysis. Pain Phys. 2018;21:433-48.

28. Lee JH, Kim DH, Kim DH, et al. Comparison of clinical efficacy of epidural injection with or without steroid in lumbosacral disc herniation: a systematic review and meta-analysis. Pain Phys. 2018;21:449-68.

29. Manchikanti L, Knezevic NN, Parr A, Kaye AD, Sanapati M, Hirsch JA. Does epidural bupivacaine with or without steroids provide long-term relief? A systematic review and meta-analysis. Curr Pain Headache Rep. 2020;24:26.

30. Knezevic NN, Manchikanti L, Urits I, et al. Lack of superiority of epidural injections with lidocaine with steroids compared to without steroids in spinal pain: a systematic review and meta-analysis. Pain Phys. 2020;23:S239-70.

31. Manchikanti L, Knezevic NN, Sanapati SP, Sanapati MR, Kaye AD, Hirsch JA. Is percutaneous adhesiolysis effective in managing chronic low back and lower extremity pain in post-surgery syndrome: a systematic review and meta-analysis. Curr Pain Headache Rep. 2020;24:30.

32. Manchikanti L, Knezevic NN, Sanapati MR, Boswell MV, Kaye AD, Hirsch JA. Effectiveness of percutaneous adhesiolysis in managing chronic central lumbar spinal stenosis: a systematic review and meta-analysis. Pain Phys. 2019;22:E523-50.

33. Manchikanti L, Soin A, Boswell MV, Kaye AD, Sanapati M, Hirsch JA. Effectiveness of percutaneous adhesiolysis in post lumbar surgery syndrome: a systematic analysis of findings of systematic reviews. Pain Phys. 2019;22:307-22.

34. Manchikanti L, Sanapati J, Benyamin RM, Atluri S, Kaye $\mathrm{AD}$, Hirsch JA. Reframing the prevention strategies of the opioid crisis: focusing on prescription opioids, fentanyl, and heroin epidemic. Pain Phys. 2018;21:309-26.

35. Manchikanti L, Singh V, Benyamin RM, Kaye AD, Pampati V, Hirsch JA. Reframing Medicare physician payment policy for 2019: a look at proposed policy. Pain Phys. 2018;21:415-32.

36. Chakravarthy K, Manchikanti L, Kaye AD, Christo PJ. Reframing the role of neuromodulation therapy in the chronic pain treatment paradigm. Pain Phys. 2018;21:507-13.

37. Manchikanti L, Sanapati MR, Pampati V, Boswell $\mathrm{MV}$, Kaye $\mathrm{AD}$, Hirsch JA. Update on reversal and decline of growth of utilization of interventional techniques in managing chronic pain in the Medicare population from 2000 to 2018. Pain Phys. 2019;22:521-36.

38. Wilson N, Kariisa M, Seth P, Smith H 4th, Davis NL. Drug and opioid-involved overdose deaths-United States, 2017 2018. MMWR Morb Mortal Wkly Rep. 2020;69:290-7.

39. Gladden RM, O'Donnell J, Mattson CL, et al. Changes in opioid-involved overdose deaths by opioid type and presence of benzodiazepines, cocaine, and methamphetamine-25 States, JulyDecember 2017 to January-June 2018. MMWR Morb Mortal Wkly Rep. 2019;68:737-44.

40. NIDA. Overdose Death Rates. National Institute on Drug Abuse website. 2020. https://www.drugabuse. gov/drug-topics/trends-statistics/overdose-deathrates. Accessed 10 Jul 2020.

41. Ahmad FB, Rossen LM, Sutton P. Provisional drug overdose death counts. National Center for Health Statistics. 2020. Available at https://www.cdc.gov/ nchs/nvss/vsrr/drug-overdose-data.htm.

42. American Medical Association. Opioid Task Force 2020 Progress Report. Physicians' Progress toward ending the nation's drug overdose and death epidemic. 2020. https://www.ama-assn.org/system/ files/2020-07/opioid-task-force-progress-report.pdf. Accessed 27 Jul 2020.

43. IQVIA $^{\mathrm{TM}}$ Institute for Human Data Science Releases 2019 Medicines Report on U.S. Drug Consumption; U.S. Rx Opioid Volume Declined 17\% in 2018Largest Single-Year Drop Ever Recorded. 2018. https://www.iqvia.com/newsroom/2019/05/iqviainstitute-for-human-data-science-releases-2019medicines-report-on-us-drug-consumption-us-rx-o. Accessed 27 Jul 2020.

44. Choinière $\mathrm{M}$, Dion $\mathrm{D}$, Peng $\mathrm{P}$, et al. The Canadian STOP-PAIN project - Part 1: Who are the patients on the waitlists of multidisciplinary pain treatment facilities? Can J Anaesth. 2010;57:539-48.

45. Eccleston C, Blyth FM, Dear BF, et al. Managing patients with chronic pain during the COVID-19 outbreak: considerations for the rapid introduction 
of remotely supported (eHealth) pain management services. Pain. 2020;161:889-93.

46. Chang HY, Daubresse M, Kruszewski SP, Alexander GC. Prevalence and treatment of pain in EDs in the United States, 2000 to 2010. Am J Emerg Med. 2014;32:421-31.

47. IQVIA. Monitoring the impact of COVID-19 on the pharmaceutical market. 2020. https://www.iqvia. com/locations/united-states/events/2020/06/ monitoring-the-impact-of-covid-19-on-the-uspharmaceutical-market. Accessed 20 Jul 2020.

48. Manchikanti L, Kaye AM, Knezevic NN, et al. Responsible, safe, and effective prescription of opioids for chronic non-cancer pain: American Society of Interventional Pain Physicians (ASIPP) guidelines. Pain Phys. 2017;20:S3-92.

49. Richter F. The deadly toll of America's opioid crisis. Statista. 2020. https://www.statista.com/chart/ 22118/drug-related-deaths-per-million-people/. Accessed 14 Jul 2020.

50. Dowell D, Haegerich TM, Chou R. CDC guideline for prescribing opioids for chronic pain-United States, 2016. MMWR Recomm Rep. 2016;65:1-49.

51. U.S. Department of Health and Human Services. Pain Management Best Practices Inter-Agency Task Force. Final report on pain management best practices: updates, gaps, inconsistencies, and recommendations. 2019. https://www.hhs.gov/ash/ advisory-committees/pain/reports/index.html. Accessed 10 Jul 2020.

52. Tracking federal funding to combat the opioid crisis. 2019. https://bipartisanpolicy.org/wp-content/ uploads/2019/03/Tracking-Federal-Funding-toCombat-the-Opioid-Crisis.pdf. Accessed 10 Jul 2020 .

53. Heath C, Sommerfield A, von Ungern-Sternberg BS. Resilience strategies to manage psychological distress among healthcare workers during the COVID19 pandemic: a narrative review. Anaesthesia. 2020;10:1364-71.

54. Dubey MJ, Ghosh R, Chatterjee S, Biswas P, Chatterjee S, Dubey S. COVID-19 and addiction. Diabetes Metab Syndr. 2020;14:817-23.

55. Shanafelt TD, Hasan O, Dyrbye LN, et al. Changes in burnout and satisfaction with work-life balance in physicians and the general US working population between 2011 and 2014. Mayo Clin Proc. 2015;90:1600-13.

56. Alexander GC, Stoller KB, Haffajee RL, Saloner B. An epidemic in the midst of a pandemic: Opioid use disorder and COVID-19. Ann Intern Med. 2020;3: 57-8.

57. Kroll H, Macaulay T, Jesse M. A preliminary survey examining predictors of burnout in pain medicine physicians in the United States. Pain Phys. 2016;19: E689-96.

58. Kuy S, Gupta R, Correa R, et al. Best practices for a Covid-19 preparedness plan for health systems. NEJM Catalyst. 2020. https://catalyst.nejm.org/doi/ pdf/10.1056/CAT.20.0108. Accessed 2 Jun 2020.

59. O'Connor CM, Anoushiravani AA, DiCaprio MR, Healy WL, Iorio R. Economic recovery after the COVID-19 pandemic: Resuming elective orthopedic surgery and total joint arthroplasty. J Arthroplasty. 2020;35:S32-6.

60. Provenzano DA, Sitzman BT, Florentino SA, Buterbaugh GA. Clinical and economic strategies in outpatient medical care during the COVID-19 pandemic. Reg Anesth Pain Med. 2020;45:579-85.

61. Wang G, Zhang Y, Zhao J, Zhang J, Jiang F. Mitigate the effects of home confinement on children during the COVID-19 outbreak. Lancet. 2020;395: $945 \mathrm{e} 7$.

62. Ghosh R, Dubey MJ, Chatterjee S, Dubey S. Impact of COVID-19 on children: special focus on psychosocial aspect. Minerva Pediatr. 2020;72:226-35.

63. Muris P, Field AP. The role of verbal threat information in the development of childhood fear. "Beware the Jabberwock! Clin Child Fam Psychol Rev. 2010;13:129e50.

64. Li Q, Guan X, Wu P, Wang X, Zhou L, Tong Y, et al. Early transmission dynamics in Wuhan, China, of novel coronavirus-infected pneumonia. N Engl J Med. 2020;382:1199e207.

65. Doraiswamy S, Cheema S, Mamtani R. Older people and epidemics: a call for empathy. Age Ageing. 2020;49:493.

66. Lloyd-Sherlock PG, Kalache A, McKee M, Derbyshire J, Geffen L, Casas FG, et al. WHO must prioritise the needs of older people in its response to the covid-19 pandemic. BMJ. 2020;368:m1164.

67. Chong MY, Wang WC, Hsieh WC. Psychological impact of severe acute respiratory syndrome on health workers in a tertiary hospital. Br J Psychiatry. 2004;185:127e33.

68. McAlonan GM, Lee AM, Cheung V. Immediate and sustained psychological impact of an emerging infectious disease outbreak on health care workers. Can J Psychiatr. 2007;52:241e7. 
69. Sim K, Chua HC. The psychological impact of SARS: a matter of heart and mind. CMAJ. 2004;170:811e2.

70. Alqahtani JS, Oyelade T, Aldhahir AM, et al. Prevalence, severity and mortality associated with COPD and smoking in patients with COVID-19: A rapid systematic review and metaanalysis. PLoS ONE. 2020;15:e0233147.

71. Aggarwal G, Cheruiyot I, Aggarwal S, et al. Association of cardiovascular disease with coronavirus disease 2019 (COVID-19) severity: a meta-analysis. Curr Probl Cardiol. 2020;45:100617.

72. Olds JL, Kabbani N. Is nicotine exposure linked to cardiopulmonary vulnerability to COVID-19 in the general population? FEBS J. 2020 (Epub ahead of print).

73. Vardavas CI, Nikitara K. COVID-19 and smoking: a systematic review of the evidence. Tob Induc Dis. 2020;18:20.

74. Berlin I, Thomas D, Le Faou AL, Cornuz J. COVID19 and smoking. Nicotine Tob Res. 2020 (Epub ahead of print).

75. Zhao Q, Meng M, Kumar R, et al. The impact of COPD and smoking history on the severity of COVID-19: a systemic review and meta-analysis. J Med Virol. 2020 (Epub ahead of print).

76. Patanavanich R, Glantz SA. Smoking is associated with COVID-19 progression: a meta-analysis. Nicotine Tob Res. 2020 (Epub ahead of print).

77. Leung JM, Yang CX, Tam A, et al. ACE-2 expression in the small airway epithelia of smokers and COPD patients: Implications for COVID-19. Eur Respir J. 2020;55:2000688.

78. Cattaruzza MS, Zagà V, Gallus S, D'Argenio P, Gorini G. Tobacco smoking and COVID-19 pandemic: old and new issues. A summary of the evidence from the scientific literature. Acta Biomed. 2020;91: $106 \mathrm{e} 12$.

79. Brake SJ, Barnsley K, Lu W, McAlinden KD, Eapen MS, Sohal SS. Smoking upregulates angiotensinconverting enzyme- 2 receptor: a potential adhesion site for novel coronavirus SARS-CoV-2 (Covid-19). J Clin Med. 2020;9:841.

80. Russo P, Bonassi S, Giacconi R, Malavolta M, Tomino C, Maggi F. COVID-19 and smoking. Is nicotine the hidden link? Eur Respir J. 2020;55: 2001116 .

81. Smith JC, Sausville EL, Girish V, et al. Cigarette smoke exposure and inflammatory signaling increase the expression of the SARS-CoV-2 receptor
ACE2 in the respiratory tract. Dev Cell. 2020;53: 514-29.

82. Cai G, Bossé Y, Xiao F, Kheradmand F, Amos CI. Tobacco smoking increases the lung gene expression of ACE2, the receptor of SARS-CoV-2. Am J Respir Crit Care Med. 2020;201:1557-9.

83. Cai H. Sex difference and smoking predisposition in patients with COVID-19. Lancet Respir Med. 2020;8:e20.

84. Madison MC, Landers CT, Gu BH, et al. Electronic cigarettes disrupt lung lipid homeostasis and innate immunity independent of nicotine. J Clin Invest. 2019;129:4290-304.

85. USA Today. Fact check: to minimize coronavirus risk, use alcohol for sanitizing, not for drinking, March 20. 2020. https://www.usatoday.com/story/ news/factcheck/2020/03/20/fact-check-drinkingalcohol-wont-reducecoronavirus-risk/2881704001/. Accessed 14 Jul 2020.

86. Volkow ND. Collision of the COVID-19 and addiction epidemics. Ann Intern Med. 2020;173:61-2.

87. Shekhar S, Hannah-Shmouni F. Hookah smoking and COVID-19: Call for action. CMAJ. 2020;192: $\mathrm{E} 462$.

88. Hindustan Times. Spitting in public, chewing tobacco could spread Covid-19, govt warns, April 5. 2020. https://www.hindustantimes.com/ indianews/spitting-in-public-chewing-tobaccocould-spread-covid-19-govtwarns/storyMA3z2ztbol7tyyD1TDkAWM.html. Accessed 14 Jul 2020.

89. Mungmungpuntipantip R, Wiwanitkit V. Sharing alcoholic drinks and a COVID-19 outbreak. Alcohol Alcohol. 2020;55:343.

90. The Hindu. Congress, BJP leaders criticise Tamil Nadu's decision to reopen TASMAC liquor outlets, May 5. 2020. https://www.thehindu.com/news/ national/tamil-nadu/congress-bjp-leaders-criticisetamil-nadusdecision-to-reopen-tasmac-liquoroutlets/article31509088.ece. Accessed 14 Jul 2020.

91. Höflich A, Michenthaler P, Kasper S, Lanzenberger R. Circuit mechanisms of reward, anhedonia, and depression. Int J Neuropsychopharmacol. 2019;22: 105-18.

92. Clay JM, Parker MO. Alcohol use and misuse during the COVID-19 pandemic: a potential public health crisis? Lancet Public Health. 2020;5:e259.

93. Ornell F, Moura HF, Scherer JN, Pechansky F, Kessler F, von Diemen L. The COVID-19 pandemic and its impact on substance use: implications for 
prevention and treatment. Psychiatr Res. 2020;289: 113096.

94. Arya S, Gupta R. COVID-19 outbreak: challenges for addiction services in India. Asian J Psychiatr. 2020;51:102086.

95. Marsden J, Darke S, Hall W, et al. Mitigating and learning from the impact of COVID-19 infection on addictive disorders. Addiction. 2020;115: 1007-10.

96. Silva MJ, Kelly Z. The escalation of the opioid epidemic due to COVID-19 and resulting lessons about treatment alternatives. Am J Manag Care. 2020;26: e202-4. 